\title{
High risk sexual behavior among adolescent senior secondary school students in Nigeria
}

\author{
Louis Odeigah ${ }^{1}$, Shittu O Rasaki ${ }^{1}$, Ajayi F Ajibola ${ }^{2}$, Ameen A Hafsat ${ }^{3}$, Abdullateef G Sule ${ }^{4}$, Yusuf Musah ${ }^{5}$
}

1. Department of Family Medicine, University of Ilorin Teaching Hospital, Kwara State, Nigeria.

2. Department of Anatomy, Kwara State College of Nursing and Midwifery, Ilorin. Tel: +2347036999373 .

3. Department of Epidemiology and Community Health, Faculty of Clinical Sciences, University of Ilorin.

4. Department of Family Medicine, Ahmadu Bello University, Teaching Hospital, Zaria, Nigeria.

5. Department of Medicine, Federal Teaching Hospital Ido-Ekiti, Nigeria.

\section{Author details:}

Shittu O Rasaki Tel: +2348035062687. Email: oorelopehospital@gmail.com, Ajayi F Ajibola,Tel: +2347036999373. Email: jimmyayayi30001@yahoo.com, Odeigah O Louis,. Email: lodeigah@yahoo.com, Ameen A Hafsat: Tel: +2348033937472. Email: hafkam2005@gmail.com, Abdullateef G Sule: Tel: +2348065535088. Email: gbensule@yahoo.com, Yusuf Musah: Tel: +2348033750480. Email: yusmusah@yahoo.com

\begin{abstract}
Background: The consequences of high risk sexual practices (HRSP) are enormous among adolescent senior secondary school students. They therefore need to have sufficient knowledge of HRSP.

Aim Objectives: The study gauged the level of knowledge and perceptions of high risk sexual behavior among senior secondary school students in Ilorin, Nigeria with a view to improving their understanding of the current trends in HRSP.

This was a quantitative, cross-sectional, descriptive study of adolescent secondary school students in Ilorin East Local Government Area. Multi - stage sampling method involving 3 stages was used. A semi-structured interviewer administered questionnaire was used to obtain data. Informed consent of respondents was obtained. The data was analyzed using SPSS windows software package version 17.

Results: Majority, 305 (69.5\%) of the students were between 16 - 20 years. The major source of information was from movies, $42.5 \%$, and the internet, $24.7 \%$. Twenty-three percent $(23.1 \%)$ had poor knowledge of HRSP. Thirty-eight percent $(38.1 \%)$ did not consider indiscriminate sexual intercourse as HRSP while $27.9 \%$ still believed that unprotected sexual practice is safe. Thirty-four percent (34.2\%) did not know that sex with multiple partners is a HRSP while $34.4 \%$ did not know that oral -genital sex is unsafe. Over thirty-two (32.9\%) perceived that engaging in sex made them mature among peers. Twenty-four (24.7\%) did not perceive any danger in keeping multiple sexual partners while $15.3 \%$ would still engage in unprotected sex.

Conclusion: The students had relatively poor knowledge and perceptions of HRSP. Quite a number did not consider indiscriminate sexual intercourse as HRSP. An appreciable number did not perceive any danger in keeping multiple sexual partners or beingengaged in unprotected sex. Counselling on the dangers of HRSP should be a component of the school health services so as to curb the complications of HRSP in our secondary schools.
\end{abstract}

Keywords: Knowledge, attitude, perception, high risk sexual practices, Nigeria.

DOI: https://dx.doi.org/10.4314/ahs.v19i1.20

Cite as: Odeigah L, Rasaki SO, Ajibola AF, Hafsat AA, Sule AG, Musab Y. High risk sexual behavior among adolescent senior secondary school students in Nigeria. Afri Health Sci. 2019;19(1). 1467-1477. bttps:// dx.doi. org/10.4314/abs. v19i1.20

\author{
Corresponding author: \\ Louis Odeigah, \\ Department of Family Medicine, \\ University of Ilorin Teaching Hospital, \\ Kwara State, Nigeria. \\ Tel: +2348069048555 . \\ Email: lodeigah@yahoo.com
}

\section{Introduction}

An adolescent is defined by the National Adolescent Health Policy in Nigeria as an individual between the ages of 10 and 24 years. This age group makes up one third of Nigeria's total population of 180 million $^{1}$ whereas the World Health Organisation (WHO) ${ }^{2}$ defines an adolescent as an individual between ages 10 to 19 years. It is

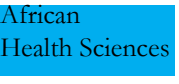

(C) 2019 Odeigah et al. Licensee African Health Sciences. This is an Open Access article distributed under the terms of the Creative commons Attribution License (https://creativecommons.org/licenses/BY/4.0), which permits unrestricted use, distribution, and reproduction in any medium, provided the original work is properly cited. 
the most turbulent stage of human development and it is characterized by indiscriminate sexual escapades. ${ }^{3}$

The National Family Health Survey (NFHS) ${ }^{4}$ defines high risk sexual behavior as sexual intercourse with somebody who is neither a spouse nor a cohabitating partner.

Factors that predispose to high risk sexual practices are: early sexual debut, cultural practices, drug abuse and illiteracy. The mean age of 15 years for sexual debut has been reported in Nigeria. ${ }^{5}$ Religion, government policies, socioeconomic status, place of residence, family, gender, constitute distant conceptual framework on adolescent sexual risk taking in Nigeria while the mass media, communication, peer influence, contraception, and early marriage constitute the proximal factors.

Adeyemo and colleagues ${ }^{6}$ in their study indicated that female adolescents with higher religiosity scores were more likely to initiate sex at a later age.. Studies have documented the association between socio-economic status and sexual behavior. ${ }^{7-8}$ High levels of family cohesion lead to bonding, and low levels of cohesion indicate poor family support, which could lead to a family dysfunction. Low family cohesion is associated with adolescent sexual risk behavior. $^{9}$

The Bello et al in their study ${ }^{10}$ showed that the mean age of sexual initiation was $15 \pm 2$.6years with more than a quarter $(28.3 \%)$ of the respondents having sexual exposure and about 40 percent having more than one sexual partner and over a third had their first sexual exposure the same day they met the partner $(37.6 \%){ }^{10}$

Multiple sex, is sexual intercourse with more than one partner. Homosexuality is romantic behaviour between members of the same sex. The most common terms for homosexual people are lesbian for women and gay for men. ${ }^{11}$ Two percent $(2 \%)$ to $13 \%$ of the world's population are homosexual.12 Having multiple sex partners is a sexual risk taking behavior. Izugbara et al showed that respondents were aware that having multiple sex partners was a risk factor for several negative health outcomes, including contracting, sexually transmitted infections STIs. ${ }^{13}$

Anal sex is sexual acts involving the anus. It involves, pegging, anilingus, fingering and object insertion. Pegging is the form of practice whereby the female wears a penis- like object and inserts it into the anus of the female partner. Anilingus is oral stimulation of a person's anus. Fingering is the insertion of fingers into the sexual part- ner's anus/vagina. The risks associated with these practices include trauma, ano-rectal fissures, rectal prolapse, infections and anal cancer. ${ }^{14}$

Oral sex is any sexual activity involving the stimulation of the genitalia by the use of the mouth and tongue. ${ }^{15}$ Terms identified in this form of sexual practice are: cumillingus which is oral sex performed by females, fellatio refers to oral sex performed by males while anilingus refers to oral stimulation of a person's anus.

Transactional sexual relationship is a situation whereby gifts, (monetary/non-monetary) and services are given or collected in exchange for sex. ${ }^{16}$ This is common in sub-Saharan Africa due to the extreme poverty in this region. ${ }^{17}$ The threat of reproductive health hazards confronting the youth in Nigeria should be a focus of research and advocacy. The problem associated with youth sexuality, such as unprotected sexual activities and inability to negotiate safe sex become readily apparent. ${ }^{18}$ This study is therefore aimed at assessing the level of knowledge of HRSB aswell as the perception of HRSP of secondary school students in Ilorin, North Central Nigeria.

\section{Methods}

Ilorin is the state capital of Kwara State with an estimated population of 847,582 as at 2007 . Ilorin metropolis consists of 3 local governments namely; Ilorin East, Ilorin West and Ilorin South which consist of 12, 12 and 11 wards respectively with numerous communities. IlorinEast local government area has an area of $486 \mathrm{~km}^{2}$ and a population of 204,310 as at 2006. Ilorin East has her headquarters in Oke-Oyi and consist of communities such as Apado, Sango, Sabo-Oke, Oke-Ose, Sobi, Maraba and Okelele among others.

This research was approved by the Ethical Committee of the Kwara State, the Kwara State Ministry of Education and the school authority. Informed consent of respondents was obtained. This was done through a section of the questionnaire in which respondents indicated their willingness to participate in the study voluntarily. Respondents were also made to understand that they could voluntarily withdraw at any time of the study.

There are 40 secondary schools in the local government area; 24 public and 16 private which have the population of senior secondary students of 8,952 and 1,170 respectively. These bring the total population of senior secondary school students in the local government area to 10,122 . It is in this local government area that we have 
prominent secondary schools such as Government Secondary School (GSS) Ilorin, Saint Anthony's Secondary School Ilorin, Cherubim and Seraphim (C\&S) College Ilorin among others. The senior secondary school curriculum mandates biology as a compulsory subject for students and parts of the body and reproduction are areas covered in this subject. This gives the students a basic knowledge and understanding of the body and sexuality. The communication channels through which information is passed to the general public in Ilorin include newspapers, radio, television, billboards and postal. There are two major television stations in the city which are Nigerian Television Authority (NTA), Ilorin and Kwara Television. The prominent radio stations based in Ilorin include Radio Kwara, Midland FM, Royal FM and Unilorin FM. The major social settings that influence sexual behaviour of adolescents in Ilorin include the presence of popular beer parlors all around the local government area. Also, female sex workers are found in identified hotels and some are also found on the streets where they receive patronage. There are also night clubs and relaxation centers that host parties and settings that create avenues for many high risk sexual practices. These places and activities influence the perception of adolescents to sexual practices since they are aware of such avenues and also sometimes they see what goes on in such places. Also, this will affect perception of lifestyle modification towards health promotion.

It is also important, to note that the Kwara state ministry of Health and Kwara State Agency for Control of AIDS (KWASACA) carry out activities on HIV/AIDS such as awareness programmes and public sensitization on the mass media among other activities. The role of the activities of non-governmental organizations (NGOs) on HIV/AIDS has also been important in the prevention and control of the disease in the local government areas and the state at large.

This was a cross-sectional, descriptive study of secondary school students in Ilorin-East local government area. Ten senior secondary students selected for the study were given interviewer administered questionnaire in order to acquire information on the knowledge, attitude and perception of high risk sexual practices.

The minimum sample size used was determined using the Andrew Fischer's ${ }^{19}$ formula for studying population greater than 10,000, degree of accuracy desired, which is set at 0.05 , standard normal deviation which is set at 1.96 which corresponds to the $95 \%$ confidence level. Prevalence of a factor within the study population $(63 \%$ - percentage of adolescents found to be already sexually active in Ilorin by Araoye and Fakeye ${ }^{20}$. The calculated sample size was 400. However, 450 was used to increase the power. Multistage sampling method involving 3 stages was used.

Stage one - There are forty (40) secondary schools in Ilorin-East local government area. Simple random sampling was used to select 10 schools out of the 40 secondary schools. This was done through balloting. The population of the senior secondary students in each of the selected schools was gotten during the advocacy visit. Proportionate allocation of respondents sampled in each of the 10 schools selected was done using the population of the schools, to estimated total population and sample size for the study.

Stage two - The class of the schools exist as natural strata. Stratified random sampling was used to determine the number of students sampled in each of the classes and arms of the selected schools. The senior secondary is divided into levels (SSI, SSII and SSIII). Also, proportionate allocation of respondents from each level was used. Total Population of Senior Secondary School Students in the 10 Schools Sampled was 6348. The Sample Size was 450 


\begin{tabular}{|l|l|l|l|l|}
\hline SCHOOL & $\begin{array}{l}\text { Number of SS1 } \\
\text { Students }\end{array}$ & $\begin{array}{l}\text { Number of SS2 } \\
\text { Students }\end{array}$ & $\begin{array}{l}\text { Number of SS3 } \\
\text { Students }\end{array}$ & $\begin{array}{l}\text { Total number of } \\
\text { Students }\end{array}$ \\
\hline School 1 & 372 & 329 & 98 & 799 \\
\hline School 2 & 111 & 142 & 90 & 343 \\
\hline School 3 & 345 & 340 & 200 & 885 \\
\hline School 4 & 57 & 54 & 31 & 142 \\
\hline School 5 & 283 & 374 & 279 & 936 \\
\hline School 6 & 111 & 129 & 90 & 320 \\
\hline School 7 & 248 & 274 & 122 & 644 \\
\hline School 8 & 417 & 306 & 196 & 919 \\
\hline School 9 & 307 & 269 & 93 & 669 \\
\hline School 10 & 307 & 277 & 97 & 681 \\
\hline Total & $\mathbf{2 5 5 8}$ & $\mathbf{2 4 9 4}$ & $\mathbf{1 2 9 6}$ & $\mathbf{6 3 4 8}$ \\
\hline
\end{tabular}

Total Population of Senior Secondary School Students $=6348$.

The Sample Size $=450$

Total number of students in each school is shown in the table above

Formula:

\section{Total number of students in each school Total Population of senior secondary school students}

\section{$\times$ sample size}

\section{Total Population of senior secondary school stu- dents}

Stage three-Simple random sampling was done to select the respondents from each of the schools and class levels. A semi-structured interviewer administered questionnaire was used as the instrument to obtain data from the respondents. The questionnaire was in three sections viz: Demographic data of the respondents, assessment of the knowledge of respondents of high risk sexual practices and assessing the perception of respondents to high risk sexual practices. Respondents were also made to understand that they could voluntarily withdraw at any time of the study. Data collected were strictly confidential.

Quantitative data was collected through the use of semistructured interviewer administered questionnaire. The data sheets were sorted, collated and coded. Data entry was carefully done. The analysis of data collected was done using SPSS windows software package version 17. The responses were coded after the collection of the raw data and were correctly analyzed based on the objectives of the study. Chi-square was used to test significance level.. Results obtained were presented as percentage and in the form of tables and charts. The total package of the analysis is a reflection of the broad objectives of the study as well as the socio-demographic data of the respondents at the level of significance at $\mathrm{P}=0.05$.

The specific objectives identified the socio-demographic variable of respondents, the level of knowledge of high risk sexual behavior as well as the perception towards high risk sexual behavior among secondary schools in Ilorin.

\section{Results}

Table 1 shows the socio-demographic characteristics of respondents. Majority 305 (69.6\%) of the respondents were between ages $16-20$ years. The male among the respondents were $254(58.0 \%)$ while the female accounted for $184(42 \%)$ respondents. The predominant religious groups were found to be Christianity and Islam accounting for $50.0 \%$ and $49.3 \%$ of respondents respectively. The Yorubas were the predominant ethnic group accounting for $342(78.1 \%)$. The other ethnic groups found among respondents classified under 'Others'include Ebira, Isoko, Ishekiri, Nupe, Fulani and Baruba. The family sizes of majority $(65.1 \%)$ of the respondents were found to be 6-10 people. 
Table 1: frequency distribution of respondents showing socio-demographic data.

\begin{tabular}{|c|c|c|}
\hline $\begin{array}{l}\text { Socio-demographic Characterisites } \\
(\mathrm{n}=438)\end{array}$ & Frequency & $\begin{array}{l}\text { Percentage } \\
\text { (\%) }\end{array}$ \\
\hline \multicolumn{3}{|l|}{ Age group in years } \\
\hline $10-15$ & 131 & 29.9 \\
\hline $16-20$ & 305 & 69.6 \\
\hline $21-24$ & 2 & 0.5 \\
\hline \multicolumn{3}{|l|}{ Class of Respondents } \\
\hline SSI & 175 & 40.0 \\
\hline SSII & 172 & 39.3 \\
\hline SSIII & 91 & 20.7 \\
\hline \multicolumn{3}{|l|}{ Gender } \\
\hline MALE & 254 & 58.0 \\
\hline FEMALE & 184 & 42.0 \\
\hline \multicolumn{3}{|l|}{ Religion of Respondents } \\
\hline CHRISTIANITY & 219 & 50.0 \\
\hline ISLAM & 216 & 49.3 \\
\hline OTHERS & 3 & 0.7 \\
\hline \multicolumn{3}{|l|}{ Ethnic Distribution } \\
\hline YORUBA & 342 & 78.1 \\
\hline HAUSA & 25 & 5.7 \\
\hline IGBO & 20 & 4.6 \\
\hline OTHERS & 51 & 11.6 \\
\hline \multicolumn{3}{|l|}{ Family Size } \\
\hline $1-5$ & 118 & 26.9 \\
\hline $6-10$ & 285 & 65.1 \\
\hline 11-ABOVE & 35 & 8.0 \\
\hline
\end{tabular}

Table 2 shows that $167(38.1 \%)$ did not consider indiscriminate sexual intercourse as HRSP while $61.9 \%$ were aware of condom use. Also, (117) $26.7 \%$ did not know that multiple sex partners is a HRSP. A proportion of 122 $(27.9 \%)$ did not know that unprotected sex with a partner of unknown status was a HRSP. Respondents' knowledge of anal sex as a HRSP showed that $150(34.2 \%)$ did not know that anal sex is a HRSP. Homosexuality was not known to be a HRSP by 156 (35.7\%). The proportion of respondents that did not know that oral-genital sex is a HRSP was 151 (34.4\%). A proportion of 305 (69.9\%) and $308(70.3 \%)$ knew that giving and receiving sex in exchange for money/gift/service are HRSP. Three hundred and five $(69.6 \%)$ knew that sex for money was a HRSP. 
Knowledge of respondents on high risk sexual practices

Table 2- frequency distribution of respondents' knowledge on high risk sexual practices

\begin{tabular}{lcc}
\hline High risk sexual practice & Frequency & Percentage (\%) \\
(N= 438) & & \\
\hline Indiscriminate Sexual Intercourse & 271 & 61.9 \\
Yes & 167 & 38.1 \\
No & & \\
Sex without using Condom & 328 & 61.9 \\
Yes & 167 & 38.1 \\
No & & \\
Multiple Sex Partners & 321 & 73.3 \\
Yes & 117 & 26.7 \\
No & & 72.1 \\
Unprotected sex & 316 & 27.9 \\
Yes & 122 & \\
No & & 65.8 \\
Anal Sex & 288 & 34.2 \\
Yes & 150 & \\
No & & 64.4 \\
Homosexuality & 282 & 35.7 \\
Yes & 156 & 69.5 \\
No & & 30.4 \\
Genito-oral Sex & 287 & 34.4 \\
Yes & 151 & \\
No & & \\
Yex for Money/Gifts/Service & 305 & \\
No & 133 & \\
Money/Gift/Services for Sex & 308 & \\
Yes & 130 & \\
No & & \\
\hline & & \\
\hline
\end{tabular}

Knowledge of respondents on high risk sexual prac- Table 3 shows the proportion of respondents who cortices rectly answered 7-10 questions on risky sexual practices.

Table 3 - frequency distribution of respondents' knowledge score on high risk sexual practices

\begin{tabular}{ccc}
\hline \multicolumn{1}{c}{ Score } & Frequency (Percentage) & Cumulative Percentage \\
\hline $\begin{array}{c}\text { Poor Knowledge } \\
(\mathbf{0 - 3 )}\end{array}$ & $101(23.1)$ & 23.1 \\
$\begin{array}{c}\text { Fair Knowledge } \\
(\mathbf{4 - 6 )}\end{array}$ & $52(11.9)$ & 34.9 \\
$\begin{array}{c}\text { Good Knowledge } \\
(7-10)\end{array}$ & $285(65.1)$ & 100.0 \\
Total & $438(100.0)$ & \\
\hline
\end{tabular}


One hundred and one (23.1\%) had poor knowledge.

Table 4 shows the frequency distribution of respondents' perception toward HRSP. One hundred and forty four $(32.9 \%)$ felt engaging in sex makes one to be considered as mature among peers while $208(47.5 \%)$ felt there was no spiritual attachment to sex. There were 56 (12.8\%) of respondents who could be friends with homosexual colleagues. Most of the respondents $333(73.7 \%)$ con- sidered it to be shameful to pay or collect money/service in exchange for sex while 108 (24.7\%) did not perceive any danger in keeping multiple sexual partners. Also, 67 $(15.3 \%)$ would still engage in unprotected sex if opportunity presented. Majority 387 (88.7) agreed that unbridled sex freedom should not be allowed while $353(80.5 \%)$ believed that students caught in any form of sexual practice should be severely punished.

Table 4 - frequency distribution of respondents' perception towards high risk sexual practices

\begin{tabular}{llll}
\hline Response & Yes (\%) & No (\%) & $\begin{array}{l}\text { Indifferent } \\
(\%)\end{array}$ \\
\hline $\begin{array}{l}\text { Engaging in sex makes one to be } \\
\text { considered matured among peers. }\end{array}$ & $144(32.9)$ & $277(63.4)$ & $17(3.9)$ \\
$\begin{array}{l}\text { Can be friends with an homosexual } \\
\text { Spiritual attachment to sex }\end{array}$ & $56(12.8)$ & $373(85.2)$ & $9(2.1)$ \\
$\begin{array}{l}\text { Sex is avoidable } \\
\text { It is a shameful thing to pay or collect }\end{array}$ & $209(47.7)$ & $208(47.5)$ & $21(4.8)$ \\
money/service in exchange for sex & $302(68.9)$ & $126(28.8)$ & $10(23)$ \\
$\begin{array}{l}\text { There is danger in multiple sex partners } \\
\text { Will engage in unprotected sex if }\end{array}$ & $319(72.8)$ & $108(24.7)$ & $11(2.5)$ \\
opportunity presents & $67(15.3)$ & $355(81.1)$ & $16(3.6)$ \\
$\begin{array}{l}\text { Any student caught in any form of sexual } \\
\text { practice should be severely punished }\end{array}$ & $353(80.5)$ & $76(17.4)$ & $9(2.1)$ \\
$\begin{array}{l}\text { Freedom to engage in sex should be } \\
\text { allowed in the school }\end{array}$ & $48(11.0)$ & $387(88.4)$ & $3(0.7)$ \\
\hline
\end{tabular}

The table 5 shows the Chi-Square tests of the relationship between age, sex, socio-demographic variables and level of knowledge on HRSP. The result of the test using a significance level of 0.05 shows that gender was found to be in a statistically significant $(\mathrm{P}$-value $<0.005)$ relationship with high risk sexual practices.

The major sources of information on high risk sexual practices among respondents was movies which accounted for $42.5 \%$ of the respondents while $24.7 \%$ got the information from the internet. 
Table 5 - frequency distribution and chi-square significance of respondents on knowledge level on high risk sexual practices and socio-demographic characteristics

\begin{tabular}{|c|c|c|c|c|c|}
\hline Variables & $\begin{array}{c}\text { Poor } \\
\text { Knowledge (\%) }\end{array}$ & $\begin{array}{c}\text { Fair knowledge } \\
(\%)\end{array}$ & $\begin{array}{c}\text { Good } \\
\text { knowledge } \\
(\%)\end{array}$ & $\begin{array}{c}\text { Chi-square } \\
\text { value }\end{array}$ & P-value \\
\hline \multicolumn{6}{|l|}{ Age } \\
\hline $10-15$ & $4(3.1)$ & $42(32.1)$ & $85(64.8)$ & 7.143 & 0.129 \\
\hline $16-20$ & $3(1.0)$ & $72(23.6)$ & $230(75.4)$ & & \\
\hline $21-24$ & $0(0.0)$ & $0(0.0)$ & $2(100.0)$ & & \\
\hline \multicolumn{6}{|l|}{ Gender } \\
\hline Male & $3(1.2)$ & $77(30.3)$ & $174(68.5)$ & 6.180 & 0.045 \\
\hline Female & $4(2.2)$ & $37(20.1)$ & $143(77.7)$ & & \\
\hline \multicolumn{6}{|l|}{$\begin{array}{l}\text { Level of } \\
\text { knowledge on } \\
\text { HSRP }\end{array}$} \\
\hline Poor & $2(2.0)$ & $33(32.7)$ & $66(65.3)$ & 4.731 & 0.316 \\
\hline Fair & $0(0.0)$ & $15(28.8)$ & $37(71.2)$ & & \\
\hline Good & $5(1.8)$ & $66(23.2)$ & $214(75.0)$ & & \\
\hline
\end{tabular}

\section{Discussion}

This study assessed the knowledge and perception of high risk sexual practices among respondents sampled from 10 senior secondary schools in Ilorin-East Local Government of Kwara State. Out of the 450 respondents sampled 438 questionnaires were valid and completed. The response rate was $97.3 \%$.

Majority of the students were between $16-20$ years and with a mean age of $16.23+4.75$. The expected age for the students in the senior secondary level of education was between 13 and 19 years. This is a reflection that they were relatively young and sexually active. This was confirmed by the National Demography Health Survey (NDHS) which revealed that nearly half $(48.6 \%)$ of adolescents aged $15-19$ were sexually active (NDHS, 2008). ${ }^{21}$

The study showed that males are more prone to high risk sexual behavior than females. This is because their libido is generally greater than that of females and continues even to old age while that of female diminishes as they get older. This made Hoffman, ${ }^{22}$ Kirby $^{23}$ and Dryfoss ${ }^{24}$ state that interventions that use attitude change to change behavior may be more effective among females than among males. Osarenren ${ }^{25}$ also stated that young men have a very strong passion about sex and they try to satisfy themselves quite indiscriminately.

The respondents were found to be mainly of the Yoruba extraction which is a reflection of the ethnic distribution of the Ilorin populace according to census and previous studies. ${ }^{26}$

The family sizes of respondents were found to be predominantly 6-10 people (65.1\%).There has been previous studies that conform to this finding. ${ }^{27,28}$ The family as a unit of care can mitigate adolescent problems. High levels of family cohesion lead to bonding and low levels of 
cohesion indicate poor family support, which could lead to a family dysfunction. Family members also exert influence on adolescents through their own modeling of risk behavior and through shared core family processes.

The cumulative knowledge on high risk sexual practices was $65.1 \%$ which is consistence with previous studies. ${ }^{29}$ About, $23.1 \%$ of respondents still have poor knowledge of high risk sexual practices which show that a proportion of secondary school students still need to be educated on high risk sexual practices. The relatively high knowledge about these high risk sexual practices should not be sufficient reason to stop discussing the perceived high level of unsafe sexuality behavior among secondary school students. ${ }^{27,30}$ Therefore, there is need to review health education strategies towards ensuring not only knowledge but also practice of safe sexual behaviour.

One third of the respondents did not consider indiscriminate sexual intercourse as HRSP. This is lower than two thirds recorded by Akanle and co-workers. ${ }^{31}$ Majority of the respondents know that unprotected sex is unsafe hence the need to be protected during sex. In this study two thirds were aware of condom use. This is comparable to the study of Folayan et al, ${ }^{32}$ but a departure from the study by Asekun - Olarinmoye and colleagues ${ }^{27}$ who reported that there was no much difference between those using condom and those who didnot.

The level of knowledge on sex for money, gifts and services being HRSP was higher than that in the study by Odu and colleagues ${ }^{33}$ in South West Nigeria where one third of the respondents received gifts or services for sex. The study established that it is shameful to pay or collect money/services in exchange for sex. At the national level, about 10 percent of females and 26 percent of males aged 15-24 years engaged in transactional sex in 2005. ${ }^{34}$ Wusu et al., ${ }^{29}$ found that factors influencing involvement in transactional sex include poverty, broken homes, peer influence and desire to make cheap money. The data from this study suggest that most students who engaged in transactional sex rarely used measures of protection such as condoms and most of the partners who engaged students in risky sexual behaviour were of higher social and economic status. ${ }^{34}$ This inequality in social and economic status makes it very difficult for the students to negotiate safe sex, hence increasing their vulnerability to sexually transmitted infections (STIs) and HIV. ${ }^{34}$
The knowledge on genito-oral sex as HRSP was higher, hence better off than that of the study of MorhasonBello $^{10}$ in Nigeria where half of the respondents practiced oral sex. Folayan et al, ${ }^{32}$ found out that oral sex was practiced by $15.1 \%$ male and $23.5 \%$ female adolescents. Male to male oral sex was reported by $7.6 \%$ adolescents while $12.0 \%$ adolescents reported female to female anal sex. Similarly, Folayan et al, also found out that anal sex was practiced by $5.6 \%$ males and $3.4 \%$ female. Male to male anal sex practice was reported by $2.2 \%$ adolescents; male to female anal sex was reported by $5.9 \%$ adolescents and female to female anal sex was reported by $0.8 \%$ adolescents. More than $11.6 \%$ males engaged in heterosexual anal sex.

Similar, multiple sex partners were recorded as HRSP by more than one third of the respondents. This is an improvement in knowledge over the two third of the respondents who practiced multiple sex in a study in South West Nigeria. The study shows that there is danger in multiple sexual partners.

Majority agreed that unbridled sex freedom should not be tolerated and those caught in any form of HRSP should be severely punished. This is in conformity with previous studies. ${ }^{16}$ This is an example of right perception that helps in preventing HRSP among secondary school students.

There are a number of sources through which information is received by the public. Higher proportion of respondents in this study identified that their major source of information on high risk sexual practices was movies and internet. Quite a considerable proportion also got information from friends and classmates. This finding is consistence with previous studies which found that movies, friends and internet are the major sources where information about high risks sexual practices were obtained. ${ }^{35}$ In some studies, school mates were key sources of information about sexual practices across the classes: some respondents in the entry class $(77.9 \%), 65.7 \%$ in the mid-class and $78 \%$ in the exit class reported that they got information about sexual practices from their school mates. More than half of the respondents in the exit class $(58.3 \%)$ reported that their source of information about sexual practices was the Internet. ${ }^{13}$

\section{Conclusion}

The knowledge and perception of HRSP among ado- 
lescents in senior secondary school in Ilorin East Local Government is poor. There are still quite a number of students who could not identify some of the high risk sexual practices while others held wrong perceptions about these practices. Therefore, there is need for health education on high risk sexual practices among these students.

\section{Conflict of interest}

None.

\section{References}

1. National Adolescent Health Policy Department of Primary Health Care and Diseases Control. Federal Ministry of Health, Nigeria. 1995. http:/ /www.k4health.org/ 2. World Health Organisation (WHO). Preventing Adolescents: A Guide to Implementing the Recommendations of World report on Adolescents and Health Geneva: WHO 2011.

3. Abodunrin OC, Olugbenga - Bello AI, Adebimpe WO. Sexual Risk Behaviour among in-school Adolescents in Public Secondary Schools South Western City in Nigeria. International Journal of Health Research. 2009; 2 (3): 241 245.

4. International Institute for Population Studies, 2007, National Family Health Survey - 3. Ministry of Health and Family Welfare, Government of India.

5. Diala C, Olujimi S, Harris F, Feyisetan K, HIV- Related Knowledge, Attitudes, Behaviours and Practices of Young People in Cross River and Kogi State, Nigeria. USAID, Washington DC, 2011, 1-4.

6. Adeyemo DA, Williams TM. Some correlates of risky sexual behavior among secondary school adolescents in Ogun State, Nigeria. Child \& Youth Services, 2010; (31):1 $-2,53-69$.

7. Zulu EM. Dodoo FN. Ezeh AC. Sexual risk taking in the slums of Nairobi Kenya, Population Studies.2002; (56): 311-323.

8. Whiteside A. 2001: AIDS and Poverty: The links. AIDS Analysis Africa 12(2): 1, 5.

9. Slap GB, Lot L, Huang B, Daniyam CA, Zink TM, Succop PA. Sexual behavior of adolescents in Nigeria: cross sectional survey of secondary school students. BMJ. 2003; 326(7379):15.

10. Morhason-Bello IO, Oladokun A, Enakpene CA, Fabamwo A O, Obisesan KA, Ojengbede. Sexual behavior of in-school adolescents in Ibadan, South-West Nigeria. $J$
Repro Health. 2008; 12(2).

11. One Love. Multiple and concurrent sexual partnerships in Southern Africa: a ten country research report. 2008.

12. Paul Van de Ven O. A Comparative Demographic and Sexual Profile of Older Homosexually Active Men, Journal of Sex Research. 1997; 34: 354

13. Izugbara CO, Modo FN, Risks and benefits of multiple sexual partnerships: beliefs of rural Nigerian adolescent males. A Jol of Men's Health. 2007; 3 (1): 197-207. 14. Miles AJ, Allen-Mersh TG, Wastell. Effect of anoreceptive intercourse on anorectal function. Journal of the Royal Society of Medicine; 1993; 86 (3) 144-147.

15. Centers for Disease Control and Prevention. 2016. "Oral Sex and HIV Risk | Factsheets | CDC HIV/ AIDS". Centers for Disease Control and Prevention.

16. Ajuwon AJ, Akin-Jimoh I, Olley BO. Sexual coercion: learning from the perspectives of adolescents in Ibadan, Nigeria. Reprod Health Matters. 2001;9(17):128-36.

17. “AIDS \& Prostitution" Avert.org. 2009-11-12. http://www.avert.org/prostitution-aids.htm. Accessed May 2012.

18. Amaziogu U, Silva N, Kaufman J, Obikeze D S. Sexual Activity and Contraceptive Knowledge and Use Among in-school Adolescents in Nigeria. International Family Perspectives. 1997; 23:28-33.

19. Fisher AA, Laing JE, Stoeckel JE, Townsend JW. Handbook for Family Planning Operation Research Design, 2nd ed. New York; Population Council: 1998:43-45. 20. Araoye M.O., Fakeye O.O. sexuality and contraception among Nigerian adolescents and youth. Afri J. Reprod Health. 1998; 2(2):142-150.

21. National Population Commission (NPC) (Nigeria) and ORC Macro. Nigeria Demographic and Health Survey 2009. Calverton, Maryland.

22. Hoffman SD. Teenage Child Bearing is not so bad after all or Is it? A review of new Literature "Family Planning perspectives"(1998) Issues 30(5) 236-239

23. Kirby, D. ( Emerging Answers: Research Findings on programmes to reduce teen pregnancy. Washington DC: (2001) National Campaign to prevent teen pregnancy.

24. Dryfoss J Adolescents at Risk: Prevailing and prevention.(2007) New York: Oxford University Press.

25. Osareren N. Child development and personality;(1998), Lagos: Debate Ltd.

26. Morhason-Bello IO, Oladokun A, Enakpene CA, Fabamwo A O, Obisesan KA, Ojengbede OA. Sexual be- 
haviour of in-school adolescents in Ibadan, South-West Nigeria, Afr J Reprod Health. 2008; 12[2]:89-97.

27. Asekun-Olarinmoye E O, Oladele E A. Condom Use among Undergraduates in Osun State, Nigeria: Implication for sexually Transmitted Infections (STIs)/HIV Prevention. Research Journal of Medical Sciences, 2009; 3(6):179187.

28. Murtala Mohammed Ruma. Knowledge and Awareness of HIV/AIDS Among Some Senior Secondary School Students In Katsina, Nigeria. 2009. Bajopas; 2(2): 121-126.

29. Wusu O. Exploring transactional sex among undergraduates and implications for sexual health. Available at : http://paa2010.princeton.edu 2011

30. Zhao Q, Li X, Stanton BTobin E A, Okojie H O. Knowledge, Attitude And Practices Of Adolescent Secondary School Students In Uvwie Local Government Area Of Delta State to HIV/AIDS. 2010 ;12 (1): 1-10 31. Akanle F, Olofintoye T. Sexual Pracrices and Attitude of Men towards prevention of HIV/AIDS in Nigeria. Journal of Emerging Trends in Educational Research and Policy Studies (JETERAPS),2010; 1(2):76-79

32. Folayan MO, Morolake O, Brandon B, Abigail H. Differences in sexual behavior and sexual practices of adolescents in Nigeria based on sex and self-reported HIV status. Reproductive Health. 2014.

33. Odu B.K., Akanle F.F., Knowledge of HIV/AIDS and Sexual Behaviour among the Youths in South West Nigeria. Humanity and Social Sciences Journal. 2008; 3(1):8188.

34. Tobin E A, Okojie H O. Knowledge, Attitude And Practices Of Adolescent Secondary School Students In Uvwie Local Government Area Of Delta State to HIV / AIDS. $2010 ; 12$ (1): 1-10

35. Carael M. Allen S. (eds.) : Women's vulnerability to HIV/STD in sub-Saharan Africa: An increasing evidence. Women's Position and Demographic Change in sub-Saharan Arica.(1995), Leige: International Union for the Scientific Study of Population (IUSSP), 201-222. 